\title{
Modelica-Based Modeling and Simulation of District Cooling Systems: A Case Study
}

\author{
Kathryn Hinkelman ${ }^{\mathrm{a}}$, Jing Wang, ${ }^{\mathrm{a}, \mathrm{b}}$, Wangda Zuo ${ }^{\mathrm{a}, \mathrm{b}, *}$, Antoine Gautier ${ }^{\mathrm{c}}$, Michael Wetter ${ }^{\mathrm{c}}$, Chengliang Fan $^{\mathrm{a}, \mathrm{d}}$, Nicholas Long \\ ${ }^{a}$ Civil, Environmental and Architectural Engineering, University of Colorado, Boulder, CO, USA \\ ${ }^{b}$ National Renewable Energy Laboratory, Golden, CO, USA \\ ${ }^{c}$ Lawrence Berkeley National Laboratory, Berkeley, CA, USA \\ ${ }^{d}$ School of Civil Engineering, Guangzhou University, Guangzhou, 510006, China
}

\begin{abstract}
While equation-based object-oriented modeling language Modelica can evaluate practical energy improvements for district cooling systems, few have adapted Modelica for this type of large-scale thermo-fluid system. Further, to our best knowledge, district cooling modeling studies have yet to include hydraulics in piping network nor waterside economizers. These are critical details to include when looking to make energy and control improvements in many physical system installations. To fill these gaps, this study applies newly developed open-source models from the Modelica Buildings library. For a real-world case study, we modeled and simulated a district cooling system at a college campus in Colorado, United States, with six buildings connected to a central chiller plant featuring a waterside economizer. Several energy saving strategies are pursued based on the validated model, including control setpoint optimization, equipment modification, and pump setpoint adjustments. Results indicate that optimizing the condenser water supply temperature setpoint can save $2.5 \%$ to $4.4 \%$ energy; the nonintegrated waterside economizer saves $6.4 \%$ energy while cutting down the chillers' run times by 201 days/year, reducing maintenance costs, and extending chiller life; and adjusting the condenser water pump flow settings can save $10.2 \%$ energy. Through a combination of the studied measures, the campus can annually save $84.6 \mathrm{MWh}$ of energy, $8.9 \%$ of electricity costs, and 58.0 metric tons of carbon dioxide emissions. Further, the numerical results of simulating districts from tens to hundreds of buildings are presented.
\end{abstract}

Keywords: District Cooling, Modelica, Modeling and Simulation, Waterside Economizer, Optimization, Numerical Performance

\section{Introduction}

Aggregating cooling equipment at the district scale provides important opportunities for cities and organizations to serve the cooling needs of their communities through financially viable means. Space cooling continues to grow faster than any other building end use [1], largely due to the improving standards of living and warming climate conditions across the globe. To meet climate action targets and reduce fossil fuel consumption, many experts recommend a shift from treating buildings as isolated entities to operating communities of buildings as interconnected systems. District cooling (DC) is one such communityscale technology that provides benefits both financially (e.g., economy of scale, centralized maintenance) and environmentally (e.g., more efficient equipment, higher renewable energy integration).

Computer modeling and simulation is an effective means to further improve the energy utilization of DC systems. Several tools have been adopted throughout literature for DC applications. Using TRNSYS, Anderson et al. [2] adjusted the operating time of chillers (compressor and absorption), cooling towers, and thermal storages with a lumped campus thermal load to minimize exergy destruction. Chow et al. [3] evaluated several water-cooled chiller plant configurations (including ther-

\footnotetext{
${ }^{*}$ Corresponding author.

Email address: wangda.zuo@colorado.edu (Wangda Zuo)
}

mal storage, several heat rejection methods, and various pumping configurations) with TRNSYS for the plant/district simulation and HEVACOMP/DOE2 for the building thermal load models. Using MATLAB, Oppelt [4] implemented dynamic thermo-hydraulic models tailored specifically for DC networks, with buildings and the central plant modeled as single heat exchangers. Some works did not present their modeling framework nor their simulation tools, yet still ought to be mentioned. For example, Gang et al. [5] evaluated chiller plants (containing electric chillers, double-effect chillers for ice production, and an absorption chiller) with ice and hydro pumped storage systems to reduce peak cooling loads. In addition, Matsouka and Hil [6] optimized the number of cooling towers and condenser water (CW) flow rate for a central plant containing turbo-chillers for an online process simulation.

However, there are limitations among these modeling tools. First, current tools generally do not consider the hydraulics in the distribution network. However, in some systems hydraulics in the distribution network has shown to have significant impact on the pump energy consumption [7], can cause controllability problems [8], and affect the effectiveness of the DC system. Second, current tools struggle to surmount the numerical hurdles of simulating large-scale models with fully-integrated plant, district, and controls. Thus, modeling simplifications had to be made by decoupling plant and district simulations or reducing the level of detail. Through these simplifications, many 
energy implications of real system features cannot be captured, such as the impact of system- and subsystem-level plant control on the DC system's transient power conditions. Lastly, many platforms, such as EnergyPlus or TRNSYS, require programmers to manually write simulation code. Those programs are based on procedural languages (e.g., FORTRAN or $\mathrm{C}++$ ), which are characteristically slow for development of heterogeneous cyber-physical models [9], including DC systems. This added task makes modeling and simulation of large, complex system models such as DC systems particularly burdensome.

Modelica [10] is a modeling language, governed by an open standard, that can effectively address these limitations. As an equation-based, object-oriented, and acausal modeling language, Modelica allows engineers to build up complex system models using a graphical, hierarchical approach, from individual equipment to subsystems and districts. From this representation, simulation code is generated automatically. Equationbased acausal modeling has proven to significantly reduce model development time [9]. For applied energy projects, the development time reductions are particularly blaring when making small design modifications in an existing model to explore different energy efficiency measures. Further, the Modelica community has rich open-source libraries, and the widevariety of solvers available in Modelica simulation environments allows the above-mentioned numerical challenges to be addressed. The case study by Zabala et al. [11] leveraged the benefits of Modelica for DC applications, creating reducedorder models of a chiller plant based on high-fidelity Modelica models for real-time, model predictive control (MPC) applications. As part of this work, the District Cooling Open Source Library was publicly released [12]. While Zabala et al. [11] developed their chiller models from Modelica, they simulated the entire DC system externally using Python. This approach was highly effective for MPC, but numerous benefits of Modelica for DC analysis remain unexplored. Beyond this work, there is surprisingly very little Modelica-based research for DC analysis.

Three principal contributions to DC modeling and simulation are made through this work. First, this is one of the first Modelica-based DC system modeling studies for detailed energy analysis that considers hydraulics in the piping networks. As such, we documented our methodology on how to model and simulate complex DC systems including a detailed plant model, the network topology, and individual building thermal models. Through this study, we added newly developed models for district heating and cooling (DHC) analysis to the the Modelica Buildings library [13], an open-source library for building energy and control systems. It should be noted that there are many similarities between heating and cooling at districtscale [14]. In addition, Modelica-based modeling of other DHC types such as combined heat and power or ambient water networks $[7,15,16]$ and chiller plants in non-DC applications $[17,18,19,20,21]$ are also extensive. However, there is a general lack of publications on DC modeling and simulation [22]. Thus, applications of DC system analysis with Modelica is an important gap addressed by this paper. Second, we evaluate the control and energy performance of a chiller plant with a waterside economizer (WSE) connected to a district network. The WSE is a "free cooling" heat exchanger that is a popular and effective way to improve chiller service life and reduce plant energy consumption [23, 24, 25]. From a modeling standpoint, Modelica is particularly suited to capture the nonlinearities present in chiller plants with WSE [26], which is not always possible with other tools. Despite their importance, to our best knowledge, others have yet to model DC systems featuring a WSE. This is another critical gap. Lastly, we evaluate the numerical performance (i.e., the scalability) of a detailed plant model connected to complete districts of several sizes. This is important to understand the capabilities and limitations of large Modelica models for DC analysis.

These contributions are presented using a validated model of an actual DC system at a satellite campus of the University of Colorado Boulder. Based on our previous work on this campus's central plant [27], this study presents a systematic methodology in modeling the DC system, adds models for the distribution network with individual building loads, and improves the central plant models. In addition, several energy efficiency measures that do not require capital investment are explored, including control setpoint optimization, assessing the effectiveness of the nonintegrated WSE, and adjusting pump setpoints. Furthermore, to quantify impacts beyond energy consumption alone, we also evaluate the financial and carbon emission savings. While these measures were explored herein, it is important to note that the model can be used for other analysis as well, such as replacing the chillers or adding thermal storage, to name a few. Although out of the scope for this case study, other approaches such as these require capital investment but can be highly lucrative.

The rest of this paper is organized as follows. To support future Modelica-based DC system studies, we summarize our systematic workflow in section 2. The case study's DC system is presented in section 3, followed by the corresponding Modelica models (section 4). After verification and validation of the DC baseline models in section 5, section 6 presents the baseline performance, energy efficiency improvements including quantification of the financial and environmental impacts, as well as the numerical performance and scalability analysis. Finally, section 7 presents our conclusions.

\section{Methodology}

As shown in Figure 1, we followed a systematic workflow for improving the energy performance of the DC system using Modelica, from problem definition to simulation-based impact evaluation. In principle, this workflow is suitable for any existing DC systems with some degree of measured data available. The following sections describe each of the eight steps in this workflow.

\subsection{Step 1: Understand the Problem}

Before collecting data or beginning modeling, it is critical to first understand the problem. This includes defining the scientific experiment and understanding what question the models 


\begin{tabular}{|c|c|c|c|c|c|c|c|}
\hline $\begin{array}{l}\text { Step 1: } \\
\text { Understand } \\
\text { the Problem }\end{array}$ & $\begin{array}{c}\text { Step 2: } \\
\text { Collect Physical } \\
\text { System Information } \\
\text { and Operational Data }\end{array}$ & $\begin{array}{l}\text { Step 3: } \\
\text { Pre-Process } \\
\text { Measured } \\
\text { Data }\end{array}$ & $\begin{array}{l}\text { Step } 4 \\
\text { Develop } \\
\text { the } \\
\text { Models }\end{array}$ & $\begin{array}{c}\text { Step 5: } \\
\text { Run } \\
\text { Numerical } \\
\text { Simulations }\end{array}$ & $\begin{array}{l}\text { Step 6: } \\
\text { Validate the } \\
\text { Baseline } \\
\text { Model }\end{array}$ & $\begin{array}{c}\text { Step 7: } \\
\text { Identify } \\
\text { System } \\
\text { Improvements }\end{array}$ & $\begin{array}{l}\text { Step 8: } \\
\text { Evaluate } \\
\text { Impacts }\end{array}$ \\
\hline
\end{tabular}

Figure 1: Workflow of the proposed methodology for Modelica-based DC system impact analysis.

should be able to answer. The goal is not to have the models represent all aspects of the real system, but only the features that are necessary per the problem objective. For example, this work aimed to study the thermo-fluid and control performance of the DC system during normal operation. Emergency protocols and atypical operating conditions were not included. Similarly, any equipment pertaining to chemical treatment was excluded. After formulating the problem, we then draw system schematics and define control inputs and loops. These schematics are invaluable blueprints for successful model development.

\subsection{Step 2: Collect Physical System Information and Opera- tional Data}

Physical system information and operational data can be used to design the system models, provide input data for the models directly, and verify and validate model accuracy. With existing DC systems, it is best to gather information and data from a variety of sources. District-scale systems often change over time as new buildings are added or plant equipment is exchanged. Thus, collecting redundant information helps verify sizing and performance specifications are up-to-date. The variety of sources includes mechanical and control specification documents, site visits (e.g., operator interviews, nameplates, control panels), and other manufacturer performance files.

\subsubsection{Electrical System}

For electrical measurement data, logged energy and power consumption of buildings and major equipment should be collected if available. Collecting real power data at 15-minute intervals is preferred for validation since it is also commonly used by electric utility companies when determining peak demand charges [28]. While equipment submetered data is the best way to validate equipment electrical performance, this is often unavailable. Thus, the electrical performance validation with measured data might only be possible at the system level, while equipment need to be validated by other means. If this is the case, equipment electrical performance can be verified with the available electrical specification documents to ensure the power is always operating within the expected range.

\subsubsection{Thermo-Fluid System}

For thermo-fluid measurement data, the plant and buildings contain sensors that log data at given intervals. We recommend the interval should preferably be no bigger than 15-minutes to capture transient dynamics of the cooling equipment as well as pumps and valves. However, to identify potential control instabilities, spot measurements may be done at shorter frequencies such as 1 minute. For chiller-only plants, it is important that the data collected span full and part load conditions at a minimum. Further, data for chiller plants with WSEs also need to include Free Cooling (FC), Mechanical Cooling (MC), and Partial MC modes, if present. In general, we recommend collecting at least two years of historical data if available to account for inevitable gaps and errors in the data sets as well as the variation of weather condition and cooling load profiles. Data types can include supply and return temperatures, mass flow rates, pump head pressure, and heat flow rates for major systems (e.g., plant, buildings) and equipment (e.g., chillers, WSE) on both the chilled water (CHW) and CW sides.

\subsection{Step 3: Pre-Process Measured Data}

Before using the data, it is necessary to pre-process the datasets so that they are suitable for use as model inputs and validation. While there are not data size restrictions on measured data for calibration purposes, data used as model inputs needs further refinement to reduce file sizes and verify expected performance. To pre-process the data, we first inspect the entire dataset for each building, plant, and equipment to see if they follow expected trends and fall within reasonable limits. Data points containing errors can then be eliminated. For example, the water in the building pipes stabilizes at the ambient room temperature $\left(20^{\circ} \mathrm{C}\right)$ when no water is flowing, which at times produces negative temperature drops due to variability across the sensor locations and sensitivity levels. These data points should be cleaned to correctly indicate zero cooling. If necessary, the datasets can be smoothed by a moving average, making it suitable for use as model inputs. For instance, CHW supply and return temperature data at the buildings can be smoothed to eliminate sensor noise from the measurements. Finally, we can round the building measured data to an appropriate decimal point to further reduce the file size for model inputs. For example, temperature measurements can be rounded to the nearest $0.1^{\circ} \mathrm{C}$ and heat flow rates to the nearest $1 \mathrm{~W}$.

\subsection{Step 4: Develop the Models}

There are numerous Modelica modeling resources available for DC system energy analysis that includes hydraulic system dynamics. Open-source libraries contain packaged models from equipment through district-scale systems that can be adapted directly or modified for case study projects. We used models from the Buildings library version 7.0.0 [13] and the Modelica Standard library version 3.2.3 [29]. For DC systems in particular, the Data Center package of the Buildings library [25] provides many equipment and subsystem models for chiller plants with and without WSE. Further, AixLib [30], IDEAS [31], and Building Systems [32] are all open-source libraries suitable for DC system model development, in addition 
to the District Cooling Open Source Library [12] previously mentioned. While models from these open-source libraries can often be used directly, it is common that custom system-level models need to be developed for the case study application. As such, we developed several new models for DHC analysis, which will be open source released in a future version of the Buildings library. This includes distribution network models from first through fifth generation DHC, standardized plant and building interconnections with interchangeable designs, and examples of complete DHC systems.

For successful model development of large-scale thermalfluid systems, compartmentalizing the system into subcomponents is key. This allows the sub-components to be tested in isolation and errors to be detected. Further, adding unit tests helps to verify that the sub-components continue to perform as expected as the model evolves. Once all sub-components have been developed and tested, then the full system model can be assembled hierarchically.

\subsection{Step 5: Run Numerical Simulations}

Modelica simulations can run in multiple environments. Dymola [33] is a popular commercial tool that provides a userfriendly graphic interface and several numerical solvers suitable for DC system analysis. The OPTIMICA Compiler Toolkit [34], with its a graphical user interface IMPACT, is also available commercially. OpenModelica [35] and JModelica [36] provide open-source environments for Modelica-based modeling and simulation. While there are many suitable numerical solvers for solving DC system models, we frequently adopt CVODE [37] for its suitability for solving stiff problems. In our experience of adopting CVODE in Dymola, it typically simulates thermo-fluid systems quickly and robustly. We run all simulations using a tolerance of $10^{-6}$.

When simulating complex thermo-system models, debugging models is often required to improve numerical performance. From our experiences, applying second-order filters to step functions (e.g., for valve opening or pump signals) often helps to improve numerical stability. Such a filter is built-in to HVAC models of many Modelica libraries. Furthermore, much attention should be paid towards PI controller gains to avoid control instability. While out of the scope of this paper, there are many resources available to help first design numericallyefficient models [38], and then simulate them effectively [39].

\subsection{Step 6: Validate the Baseline Model}

District-scale heating and cooling systems can have larger uncertainties in measured data than for individual building systems, particularly due to the lack of sufficient quantitative data at such scale [40]. While the uncertainty can have an averaging effect at district-scales for some features, it is potentially compounding for others [41]. Thus, it is important for modelers to recognize the impacts of uncertainly in measured data when validating complete DC systems. To address this challenge, we suggest verifying modeling assumptions and validating simulation results for DHC energy-based studies across two primary dimensions: (1) electrical and thermo-fluid systems; and (2) equipment and system levels.

\subsubsection{Electrical System}

For electrical validation, it is common that electrical data is available at the plant and buildings' main meters, but submetering is not available for individual equipment. Further, buildings' main meters typically have equipment beyond the cooling system. For example, central plants frequently contain both heating and cooling equipment that serve the district, as well as heating, ventilation, and air conditioning (HVAC) equipment serving the plant building itself and other electrical loads (e.g., interior and site lighting, plug loads). To address this uncertainty, we suggest to validate system level DC power consumption from simulations with respect to the range of expected $D C$ real power from measured data at the building's main electrical meter. An upper limit to DC plant power range $\bar{P}_{P l a}$ is given as

$$
\bar{P}_{P l a}=P_{M e a}
$$

where $P_{M e a}$ is the measured real power data from the electrical meter. To represent the lower limit $\underline{P}_{P l a}$, we adjust $P_{\text {Mea }}$ by scaling factor $\sigma$ using

$$
\begin{gathered}
\underline{P}_{P l a}=\sigma P_{M e a} \text { where } \\
\sigma=f \frac{\sum D_{P l a, i}}{\sum D_{P l a, i}+\sum D_{O t h, j}}
\end{gathered}
$$

In this formulation, $\sigma$ represents the ratio of the peak demands from all individual cooling plant equipment $D_{P l a, i}$ to the total peak demand of the main meter, including other loads $D_{O t h, j}$, which are not apart of the DC system. An additional safety factor $f$ of 1.25 is included to account for the likelihood of equipment operating at different part load ratios. In this case study, $\sigma$ was 0.42 . An example of such analysis is shown in Figure 9.

For equipment-level validation, submetered data should be used if available. If not, modelers can verify that the power consumption of each equipment is always at or under the stated nominal value during the annual simulation. An example of this alternate approach is shown in Figure 10, where box plots depict the annual distribution of power required for major equipment, normalized by their rated nominal powers.

\subsubsection{Thermo-Fluid System}

For thermo-fluid validation, on-site sensors provide temperature and flow rate data from various points throughout the system. Following ASHRAE Guideline 14 [42], we evaluate both the Coefficient of Variation of the Root Mean Square Error

$$
\operatorname{CVRMSE}=\frac{\sqrt{\frac{\sum\left(y_{i}-\hat{y}_{i}\right)^{2}}{N-1}}}{\bar{y}},
$$

and the Normalized Mean Bias Error

$$
N M B E=\frac{\sum\left(y_{i}-\hat{y}_{i}\right)}{(N-1) \bar{y}},
$$

where $y_{i}$ is the individual measured data, $\hat{y}_{i}$ is the corresponding simulation data, $\bar{y}$ is the mean of the measured dataset, and $N$ is the total number of data points. With hourly data, the CVRMSE 
and NMBE need to be within $30 \%$ and $10 \%$ respectively for the model to be considered validated [42].

It is important to note that ASHRAE Guideline 14 is intended for measurement of energy and demand savings. Thus, they do not provide specific guidance on temperature and mass flow measurements. However, the same standard was accepted herein across all thermo-fluid data types. For temperature, units of Kelvin were adopted, while mass flow was represented in $\mathrm{kg} / \mathrm{s}$. Furthermore, it is possible that after pre-processing and removing sensor errors, a full year of clean measured data may not be available. In this case, both system and equipment level thermo-fluid conditions can be validated using representative time periods. For instance, this study selected two representative weeks in both summer and winter to validate the system models.

\subsection{Step 7: Identify System Improvements}

With the validated baseline model, several energy efficiency improvements for the DC system can be simulated to quantify their potential benefits. While providing guidance on which energy efficiency measures to select is out of the scope of this work, other literature provide comprehensive methodologies for identifying optimal energy efficiency measures for buildings [43] and control strategies for central plants [44]. For demonstration, we selected three measures that require little to no financial investment. This includes optimizing the CW supply temperature setpoint $\left(T_{C W, s e t}\right)$, assessing the effectiveness of the WSE, and adjusting CW pump flow rate settings. These were selected after analyzing the baseline energy results and identifying high potential areas for improvement that can readily be adopted by the system operators.

As an example for the $T_{C W \text {,set }}$ optimization, we can formulate a single objective optimization problem to minimize the plant's annual energy consumption as

$$
\begin{gathered}
\min _{x \in[\underline{x}, \bar{x}]} E_{P l a, i}\left(T_{C W, s e t}(x)\right), \\
\text { with } \quad x=\left(\begin{array}{l}
x_{1} \\
x_{2}
\end{array}\right), \quad \text { and } \\
E_{P l a}\left(T_{C W, s e t}(x)\right)=\int_{t_{1}}^{t_{2}}\left(P_{C H}\left(T_{C W, s e t}(x), s\right)+\right. \\
P_{C W}\left(T_{C W, s e t}(x), s\right)+P_{C H W}\left(T_{C W, s e t}(x), s\right)+ \\
\left.P_{C T}\left(T_{C W, s e t}(x), s\right)\right) d s,
\end{gathered}
$$

where $x$ represents the free parameters to be tuned during the optimization process, $E_{P l a}$ is the total plant energy during the optimization period $t \in\left[t_{1}, t_{2}\right), P_{C H}$ is the power of the chillers, $P_{C W}$ is the power of the CW pumps, $P_{C H W}$ is the power of the CHW pumps, $P_{C T}$ is the power of the cooling towers, $x$ contains the tuner parameter lower limits, and $\bar{x}$ contains the tuner parameter upper limits.

Three separate optimization problems are solved with $T_{C W \text {,set }}$ prescribed as

$$
\begin{gathered}
T_{C W, s e t}\left(x_{1}\right)=x_{1}, \\
T_{C W, s e t}\left(x_{1}\right)=T_{w b}+x_{1}, \\
T_{C W, s e t}\left(x_{1}, x_{2}\right)=T_{w b}+x_{1}+x_{2} P L R,
\end{gathered}
$$

where in Equation 9, $T_{C W, \text { set }}$ is a fixed temperature (Fixed $T_{C W, \text { set }}$ ) equal to constant $x_{1}$; in Equation $10, T_{C W, \text { set }}$ is a fixed approach temperature (Fixed $T_{a p p}$ ) equal to $x_{1}$ offset from the measured ambient wetbulb temperature $T_{w b}$; and in Equation $11, T_{C W \text {,set }}$ is an adjusted approach temperature (Adjusted $T_{a p p}$ ) offset $x_{1}$ from $T_{w b}$ and scaled by $x_{2}$ based on the central plant's part load ratio $P L R$. In this case study, optimization problems are solved for $t \in[0,365)$ days with the Optimization library version 2.2.4 [45] using the local simplex method. Optimization and simulation tolerances of $10^{-5}$ and $10^{-6}$ respectively are used.

\subsection{Step 8: Evaluate Impacts}

Beyond energy consumption alone, evaluating the impacts that cooling infrastructure has on humans and the environment require higher-level evaluation metrics. Our approaches are as follows.

\subsubsection{Energy Impacts}

There are several metrics available to evaluate energy impacts for DC systems. Annual site and source energy consumption are two common metrics. In addition, peak power is a helpful indicator to understand the instantaneous rate of energy required at a given time. For cooling plants, the plant efficiency is often represented by $\mathrm{kW} / \mathrm{ton}$. This is defined as the ratio of total cooling plant power (including chillers, pumps, and cooling tower fans) to the total cooling load served by the plant. For chillers, the $\mathrm{kW} /$ ton is also a common metric to represent the equipment energy efficiency ratio. Similarly, the coefficient of performance is used as an equipment or system efficiency indicator. This is a unitless value representing the ratio of the cooling load to the electrical power. For buildings, common energy metrics also include the energy use intensity (ratio of cooling energy to total floor area served). In this study, we adopt the annual site energy consumption as the primary energy impact metric but also assess the $\mathrm{kW} /$ ton and peak power.

\subsubsection{Economic Impacts}

We evaluate the annual cost of electricity for operating the DC system based on the electric rate schedule from the local utility. While many electric utilities employ static pricing programs, there are increasing trends towards dynamic pricing programs (e.g., critical peak pricing, time of use pricing). Because the return on investment of different energy efficiency measures is often sensitive to the pricing program [46], it is important to represent the pricing scheme accurately. As an example for this case study, we adopt the static pricing program assigned to the central plant. In this case, electricity is charged on a monthly basis $\$ 0.00458$ per $\mathrm{kWh}$ of energy used and $\$ 3.86$ per $\mathrm{kW}$ of billing demand.

\subsubsection{Environmental Impacts}

Representative environmental indicators can be selected based on previous knowledge of the life cycle impacts of building systems. Operational phase energy consumption dominates 
typical building life cycle impacts and its greenhouse gas emissions represent the largest impact category [47]. This is particularly true for cooling plants where their primary function is to produce $\mathrm{CHW}$ for the district. Although calculating greenhouse gas emissions would be more comprehensive for assessing climate impacts, carbon dioxide $\left(\mathrm{CO}_{2}\right)$ is the dominating byproduct of fossil fuel-based electricity generation. Thus, it is reasonable to use $\mathrm{CO}_{2}$ as a proxy indicator. To calculate $\mathrm{CO}_{2}$, Cambium's datasets provide hourly cost and operational data for the U.S. electricity sector [48]. For this case study, we adopt Cambium's 2018 Midcase Scenario data for the average $\mathrm{CO}_{2}$ emission rate $(\mathrm{kg} / \mathrm{MWh})$ of generation induced by Colorado's regional load. This dataset provides hourly carbon emissions based on the dynamic electricity mix for the state, including intermittent renewable generation, while also including the effects of imported and exported power as well as distribution losses.

\section{System Description}

A case study of DC system modeling and optimization is conducted using the methodology mentioned in section 2 . The case study site is a satellite campus of the University of Colorado Boulder with DC services provided to six buildings. This section describes the analyzed system, including the distribution network, the central plant, and the connected buildings.

\subsection{Distribution Network}

The distribution network is a radial layout (Figure 2) connecting six buildings with a central plant. The total length of supply and return pipes is around $1.5 \mathrm{~km}$. The pipes can be divided into 11 segments. Some segments are insulated pipes located in underground tunnels while others are direct buried. Additional information for the district pipes can be found in the Appendix (Table A.1).

\subsection{Central Plant}

As shown in Figure 3, the primary-only central plant includes two water-cooled chillers with a parallel WSE on both the CHW and CW legs. This WSE configuration is commonly referred as nonintegrated, and the WSE can only run when it is capable of meeting the entire cooling load. In contrast, an integrated WSE is in series with the chillers on the CW or CHW legs, such that the WSE can share the cooling load with the chillers when it cannot meet the entire demand. At this plant, $\mathrm{CW}$ is cooled by two open-circuit cooling towers before returning to the chillers/WSE. The nominal power for each chiller compressor (2 chillers total, 1 compressor per chiller), CW pump (2 total), CHW pump (3 total), and cooling tower fan (4 total) is $366 \mathrm{~kW}, 56 \mathrm{~kW}, 30 \mathrm{~kW}$, and $22 \mathrm{~kW}$, respectively. The plant's hierarchical control is implemented through a Supervisory Control and Data Acquisition system; at top Master Control level, the plant operates in either MC mode (running the chillers only) or FC mode (running the WSE only). Further details about the mechanical and control system configurations, including system schematics and nominal information for the plant equipment, can be found in [27].

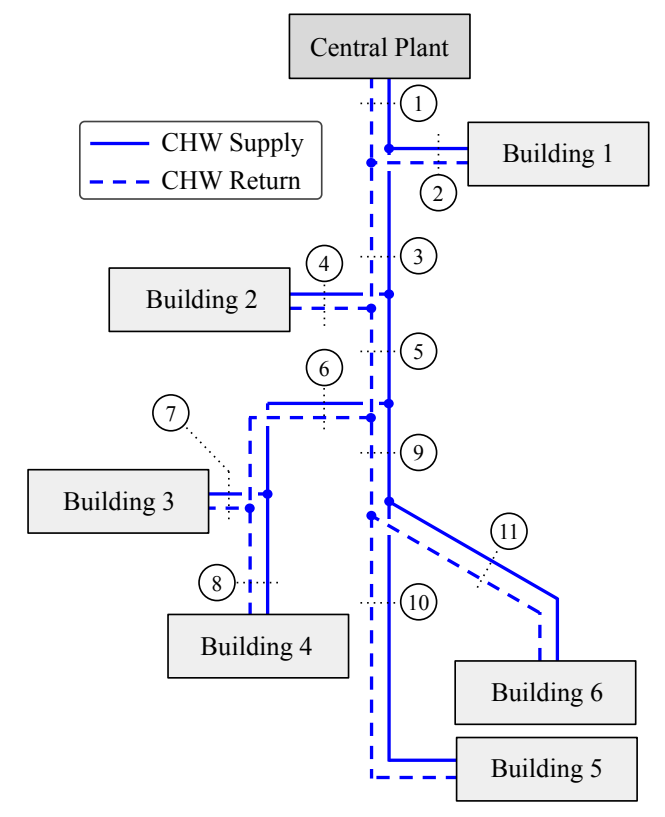

Figure 2: Network topology for the DC system. Details about the numbered pipe segments are given in the Appendix (Table A.1).

Table 1: Buildings connected to the district network.

\begin{tabular}{lrr}
\hline Building No. & Area $\left(\mathrm{m}^{2}\right)$ & Primary Function \\
\hline 1 & 13,126 & Dormitory/Classrooms \\
2 & 23,170 & High-rise Dormitory \\
3 & 11,420 & High-rise Dormitory \\
4 & 10,680 & Dining and Recreation \\
5 & 17,730 & Mid-rise Apartments \\
6 & 17,730 & Mid-rise Apartments \\
\hline
\end{tabular}

\subsection{Connected Buildings}

The serviced buildings are primarily student dormitories with some academic and dining functions (Table 1). Each building is connected to the district via an energy transfer station (ETS) with a direct piping connection (no heat exchanger). A bypass loop at the ETS maintains minimum CHW return temperatures to the district. The six buildings account for a total of $93,990 \mathrm{~m}^{2}$ gross floor area, while the cumulative peak load across all buildings is $1,772 \mathrm{~kW}$. Like many district energy projects, the campus originally anticipated more buildings being added to the site than exists currently. As such, the sizing of the central plant accounted for an additional twelve buildings which have not been constructed yet.

The measured load duration curves from this site (Figure 4) show how the cooling needs vary from building to building in 2018. The CHW heat flow rate is calculated using the supply and return temperature and mass flow rate sensors at each building's ETS. For example, the peak cooling demands range from $248 \mathrm{~kW}$ (building 1) to $653 \mathrm{~kW}$ (building 2). During 2018, buildings 2 and 4 had cooling demand year-round, while building 3 had cooling needs for only $40 \%$ of the year. The total cooling load varies from 1,263 MWh/year for building 4 to $246 \mathrm{MWh} /$ year for building 1. 


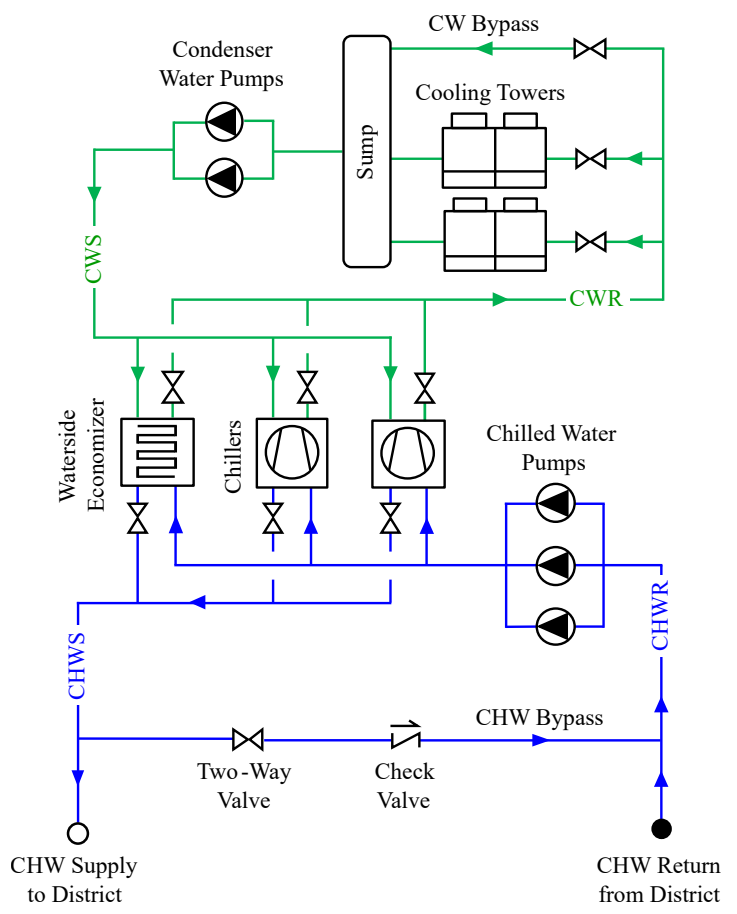

Figure 3: Schematic diagram for the central plant.

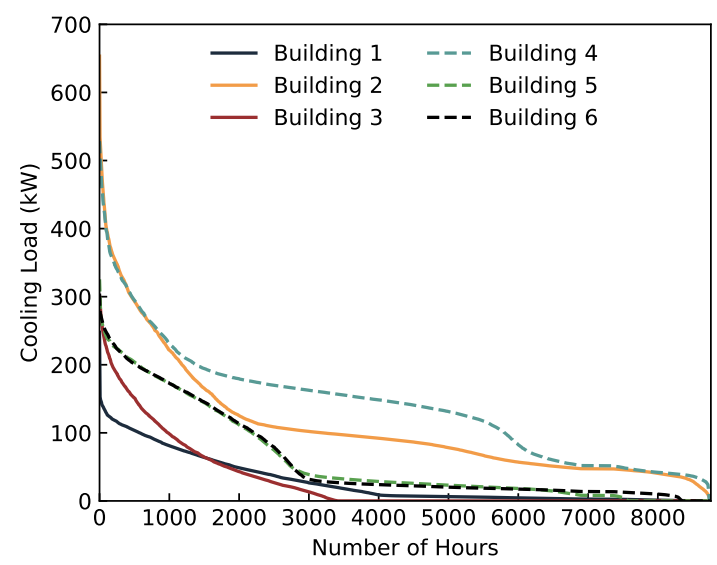

Figure 4: Cooling load duration curves from 2018 measured data.

\section{Modelica Implementation}

The DC system is modeled using the Modelica language and open-source components from the Buildings and Modelica Standard libraries. New system and equipment-level models were developed as part of this project, which will be opensource released in the Buildings library. The system models are presented in a top-down approach in the following sections.

At the top level, the Modelica DC system model (Figure 5) includes a central plant, a distribution network, and interconnected buildings. With a vector of fluid connectors in the Distribution Network model, a district with any number of buildings can quickly be represented, given that the computer has sufficient resources to solve the problem. Through packaged hierarchical modeling, each major DC component can seamlessly

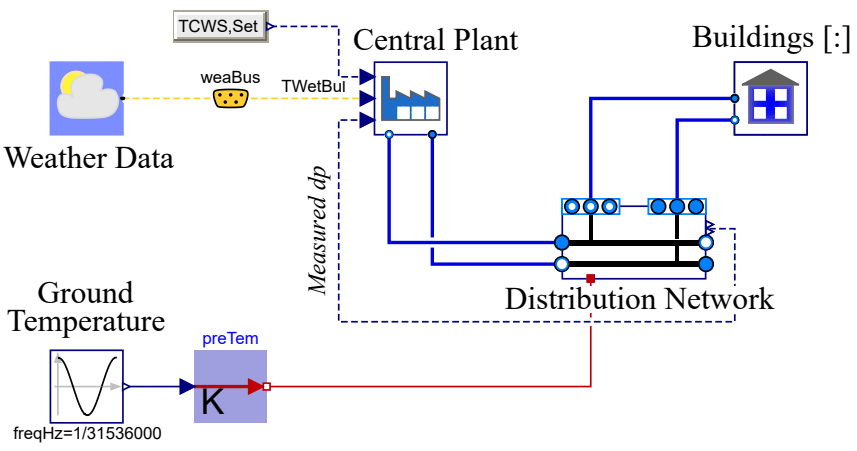

Figure 5: Top level diagram of Modelica model for the DC system.

be replaced; for example, high-order or reduced-order building models can be integrated into the flexible modeling framework.

\subsection{Boundary Conditions}

Modeled weather and ground conditions are consistent with the local environment. Historical 2018 weather data from onsite sensors were collected and averaged on an hourly basis. We then overwrote the ambient drybulb temperature, dew point, relative humidity, and barometric pressure data from a typical meteorological year 3 (TMY3) data set corresponding to a regional weather station with the on-site data. The TMY3 file was then imported via the Weather Data block from the Buildings library, in which $T_{w b}$ is calculated. We assumed the tunnel temperature is the same as the ground three meters below the surface, represented by a sinusoid ranging from $4.6^{\circ} \mathrm{C}$ (March) to $15.9^{\circ} \mathrm{C}$ (September). This is consistent with average regional ground temperatures. Since we used measured data for the building loads, the model is not using solar irradiation data. Hence, overriding only the temperature data still provides consistent boundary conditions.

\subsection{Distribution Network}

A vector-style distribution network model was developed to allow interconnection with any number of buildings. Shown in Figure 6, the Distribution Network model consists of a series of Connection models. Supply and return pipes between each connection are modeled as plug flow pipes (using the model Buildings.Fluid.FixedResistances.PlugFlowPipe). Developed with DHC in mind, this pipe model efficiently and accurately evaluates pipe pressure drop, heat losses through the distribution network, and fluid transport delay. It also produced the smallest errors in comprehensive DHC experiments compared to other available models. More information about this pipe model can be found in [49].

\subsection{Central Plant}

The detailed central plant model represents the physics of the real mechanical and control systems. Modelica diagrams and model details about the central plant can be found in [27].

Contrary to many past DC modeling projects, this work included pump models at the central plant that reflect the performance curves of the installed equipment. For example, the case 


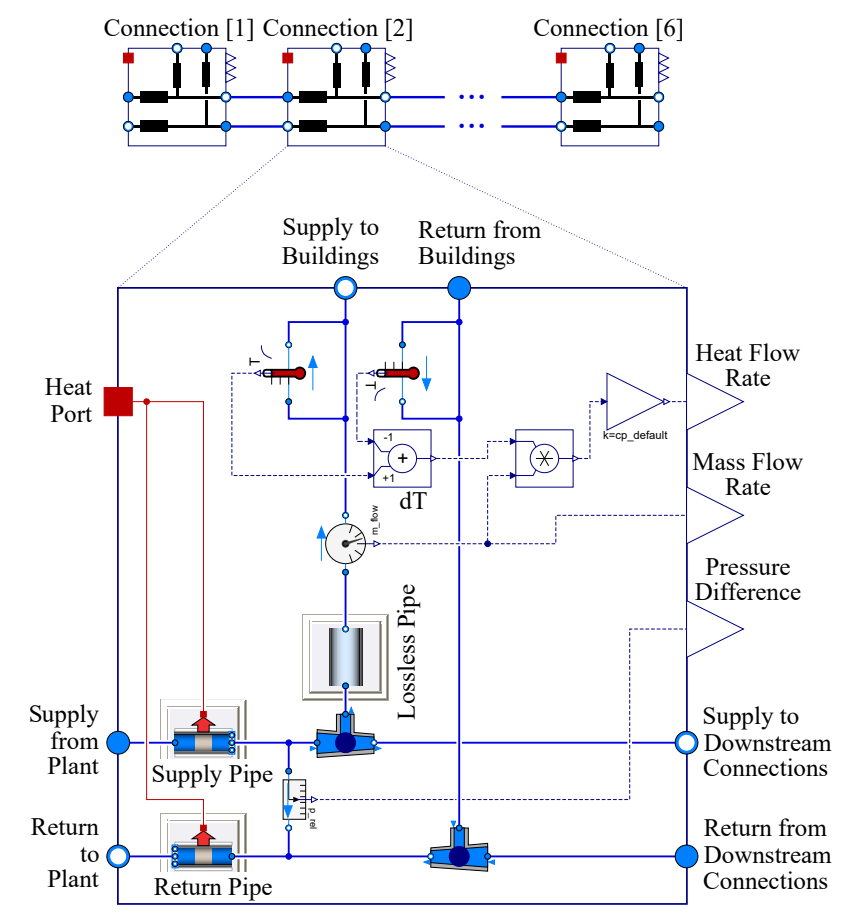

Figure 6: Hierarchical diagram of vector-style network interconnection model.

study by Zabala et al. [11] assumed the pumping power was negligible, since their energy consumption was much smaller than the chillers. In contrast, the pumping power in this central plant is far from negligible, as is shown in Section 6.1 below. Indeed, pumping energy for large DC systems is often a major contributor to the overall energy consumption, and others have focused solely on different pumping configurations in order to save energy [50].

In Figure 7, the CW pump curves are shown as an example. When looking to revise flow setpoints during MC and/or FC modes, it is important to ensure that the minimum flow does not surpass the minimum continuous stable flow (MCSF) point. As an upper limit, the pump is restricted by the maximum power of the motor. Further, there are system-level limitations on the flow rate as well, including the minimum flow required by the cooling towers to keep the surfaces wetted, the minimum condenser flow required by the chillers, and the minimum pump speed required to meet the cooling towers' static lift [51].

\subsection{Connected Buildings}

Because the CHW supply and return temperatures and the mass flow rate are metered at the ETS, building models were created to accept these tabulated data files directly. The building model (Figure 8) includes the district-side CHW piping and equipment. The rejected heat from the building's cooling equipment is transferred to the district's CHW at the ETS (using the model Buildings.Fluid.HeatExchangers.Heater_T). This model measures the CHW supply temperature, and returns the $\mathrm{CHW}$ based on the tabulated temperature difference. The control valve modulates the flow to match the tabulated mass flow rate for each building.
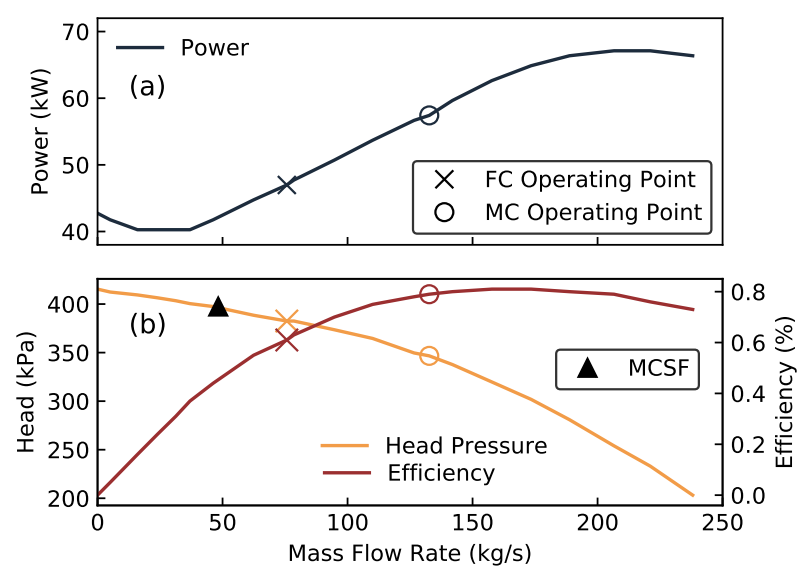

Figure 7: Condenser water pump performance curves for (a) electrical power and (b) head pressure and efficiency, adapted from manufacturer documents.

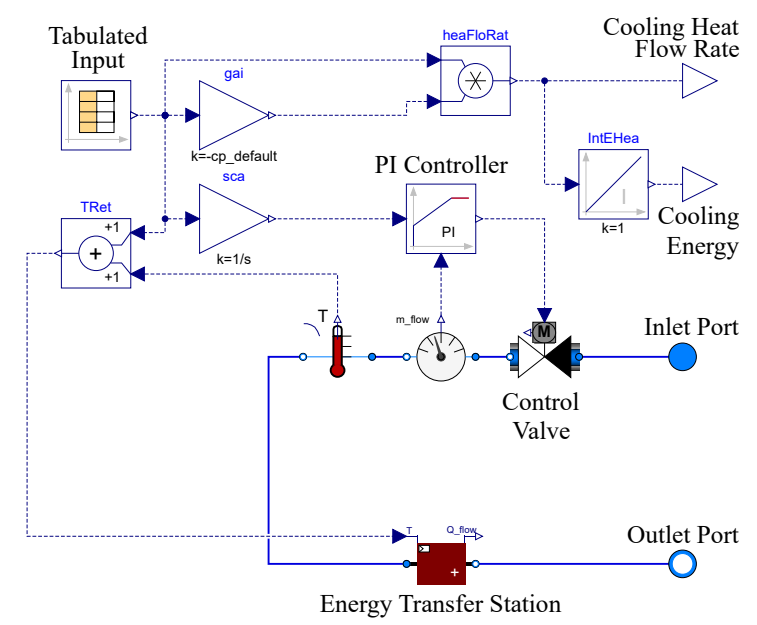

Figure 8: Diagram of the time series building model.

As seen in Figure 8, the building-side HVAC systems (including the primary $\mathrm{CHW}$ pumps), piping, and thermal zones are not modeled. Therefore, the heat transferred at each building represents the metered heat flow rather than the cooling loads at the thermal zones. Some limitations of this approach are that (1) some design optimization between building and district operation cannot be tested and (2) the thermal comfort at the rooms cannot be verified. However, the simplification does provide an accurate and numerically efficient implementation for time series loads metered at the ETS, which is commonly available among existing DC systems. Models to be added to the library will include lumped thermal zone load models to increase the flexibility of the modeling platform.

\section{Verification and Validation}

\subsection{Electrical System}

The central plant's electric power was validated with historical metered data from the plant's main electrical meter (see Figure 9) since there was no submetering for the central plant. The extra power in the measurement includes HVAC for the plant, 
the district heating plant, and other site loads. Within the limits of expected uncertainty, the simulated DC power matched the expected range of real central plant power from measured data. The upper and lower limits of this expected power range were determined using the methodology described in section 2.6.1. While this approach was necessary in this case study based on the available measured data, the validation could be improved by installing submeters on major cooling equipment.

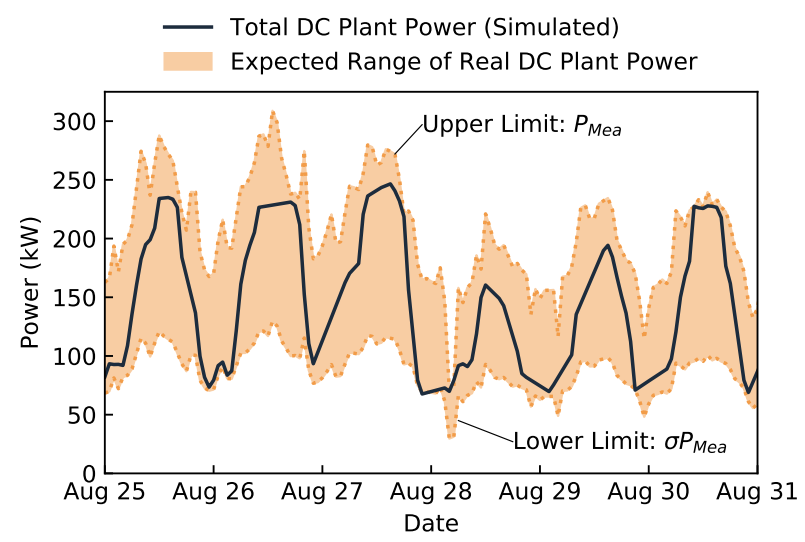

Figure 9: Validation results of the electrical system.

For equipment-level validation, the electrical power of each equipment operated at or below their nominal rated power throughout the entire annual simulation (Figure 10). The box plot effectively depicts the distribution characteristics of each equipment's power consumption, normalized by the nominal rated power of each equipment. In Figure 10, the thick middle line represents the median, the upper and lower ends of the box represent the upper and lower quartiles, the whiskers represent power rates outside of the middle $50 \%$, and the circles depict the outliers. In this simulation, while the chillers, CW pumps, and CHW pumps tended to run at low part load ratios, the cooling tower fans frequently ran at full power.

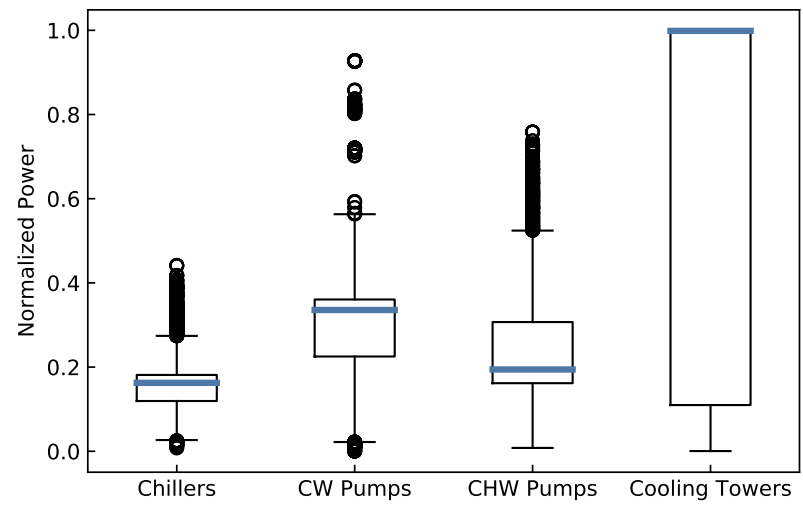

Figure 10: Validation results of major central plant equipment.

\subsection{Thermo-Fluid System}

Two typical periods from summer (Aug. 1-14, 2018) and winter (Jan. 28-Feb. 11, 2018) seasons were selected for thermo-fluid validation. The results are summarized in Table 2 for the summer period and Table 3 for the winter period. On an hourly basis, the simulations fell within the acceptable ranges of modeling uncertainty for all locations. Please note that the acceptable ranges per ASHRAE Guideline 14 [42] depend on the measurement frequency (e.g., hourly, monthly) and other factors. The acceptable ranges quoted are specifically for hourly calibration with whole building simulation. During the summer period, the plant operated in MC mode with the chiller meeting the entire cooling demand. The buildings were well controlled across all data types, and temperature errors were small across all locations.

During the winter period, the plant operated in FC mode, with the WSE meeting the entire cooling demand. Two buildings ( 1 and 3 ) did not have a cooling load during this period, and thus were excluded from winter validation. Similar to the summer period, all simulation test locations fell within the acceptable ranges of modeling uncertainty, as seen in Table 3. By validating the DC model across multiple layers and system types, we can gain confidence in the model's representation of the real system for further energy analyses.

\section{Results and Discussion}

\subsection{Baseline Energy Performance}

In the annual simulation, the central plant consumed $552 \mathrm{MWh}$. As seen in Figure 11, the CW pumps represented the major energy consumer in the cold months, while the chillers were the major consumer in the hot months. Producing 3,878 MWh of cooling energy for the year, the cooling plant operated with an average COP of 7.03. The chillers, CW pumps, CHW pumps, and cooling tower fans were responsible for $41.4 \%, 37.1 \%, 10.8 \%$, and $10.8 \%$ of the plant's annual energy consumption, respectively. As expected, the plant's energy consumption was the highest in the summer, but a minimum monthly load of 21.3 MWh was maintained (February 2018). In colder seasons, the CW pumps dominated the plant's energy consumption for three main reasons: (1) two pumps run during FC mode while only one pump runs during MC mode when one chiller is on; (2) the $\mathrm{CW}$ pumps operate at a lower efficiency during FC than MC (as shown in Figure 7); and (3) the CW side of the WSE has higher-pressure resistance compared to the chiller's condenser.

Figure 12 shows the detailed analysis of the central plant operation for two sample windows during FC (Feb. 13-18, 2018) and MC (Aug. 19-24, 2018) modes. During FC mode, the plant's overall $\mathrm{kW} /$ ton was higher than that during MC mode. This surprising result is primarily due to (1) the lower cooling load during FC (260 kW average during the mid-February week compared to $2,700 \mathrm{~kW}$ during the late August week) and (2) the higher power required for the $\mathrm{CW}$ pumps during $\mathrm{FC}$ mode. Even though the cooling load is small during FC mode, the plant still needs to run equipment at their minimum limits. Conversely, the high-efficiency, variable speed, variable flow chillers during MC mode allow the chillers to operate at higher efficiency while serving larger cooling loads. During FC 
Table 2: Validation results for a typical summer period.

\begin{tabular}{|c|c|c|c|c|c|c|c|c|}
\hline \multirow[t]{2}{*}{ Location } & \multicolumn{4}{|c|}{$\begin{array}{c}\text { CVRMSE }(\%) \\
\text { Acceptable Range: }[0,30 \%]\end{array}$} & \multicolumn{4}{|c|}{$\begin{array}{c}\text { NMBE }(\%) \\
\text { Acceptable Range: }[-10,10 \%]\end{array}$} \\
\hline & $\dot{Q}_{C H W}$ & $\dot{m}_{C H W}$ & $T_{C H W S}$ & $\overline{T_{C H W R}}$ & $\dot{Q}_{C H W}$ & $\dot{m}_{C H W}$ & $T_{C H W S}$ & $T_{C H W R}$ \\
\hline Plant & 18.8 & 12.9 & 0.3 & 0.2 & 9.7 & 7.4 & -0.1 & -0.1 \\
\hline Chiller & 22.2 & 15.5 & 0.2 & 0.3 & 8.7 & 7.4 & -0.1 & -0.1 \\
\hline Building 1 & 2.2 & 0.7 & 0.2 & 0.2 & 0.04 & 1.1 & 0.1 & 0.2 \\
\hline Building 2 & 2.4 & 0.1 & 0.2 & 0.2 & 0.02 & 0.6 & -0.01 & -0.02 \\
\hline Building 3 & 3.6 & 0.4 & 0.3 & 0.3 & 0.02 & 0.8 & 0.2 & 0.2 \\
\hline Building 4 & 1.3 & 0.7 & 0.2 & 0.2 & -0.02 & -0.1 & 0.04 & 0.04 \\
\hline Building 5 & 1.6 & 0.4 & 0.2 & 0.2 & 0.04 & 0.4 & 0.08 & 0.07 \\
\hline Building 6 & 2.2 & 0.5 & 0.2 & 0.2 & -0.05 & 0.5 & 0.01 & 0.01 \\
\hline
\end{tabular}

Table 3: Validation results for a typical winter period. Buildings with a ${ }^{\star}$ had zero cooling demand during the winter period.

\begin{tabular}{|c|c|c|c|c|c|c|c|c|}
\hline \multirow[t]{2}{*}{ Location } & \multicolumn{4}{|c|}{$\begin{array}{c}\text { CVRMSE }(\%) \\
\text { Acceptable Range: }[0,30 \%]\end{array}$} & \multicolumn{4}{|c|}{$\begin{array}{c}\text { NMBE }(\%) \\
\text { Acceptable Range: }[-10,10 \%]\end{array}$} \\
\hline & $\dot{Q}_{C H W}$ & $\dot{m}_{C H W}$ & $T_{C H W S}$ & $T_{C H W R}$ & $\dot{Q}_{C H W}$ & $\dot{m}_{C H W}$ & $T_{C H W S}$ & $T_{C H W R}$ \\
\hline Plant & 14.6 & 3.1 & 0.2 & 0.3 & -0.2 & 2.5 & 0.1 & 0.1 \\
\hline WSE & 15.6 & 3.1 & 0.3 & 0.2 & 7.3 & 2.5 & 0.1 & 0.1 \\
\hline Building $1^{\star}$ & - & - & - & - & - & - & - & - \\
\hline Building 2 & 3.9 & 0.1 & 0.3 & 0.3 & -0.02 & 0.3 & -0.1 & -0.1 \\
\hline Building $3^{\star}$ & - & - & - & - & - & - & - & - \\
\hline Building 4 & 2.3 & 0.8 & 0.3 & 0.3 & 0.1 & 0.6 & 0.03 & 0.02 \\
\hline Building 5 & 10.0 & 1.4 & 0.3 & 0.3 & 0.2 & 6.3 & 0.1 & 0.1 \\
\hline Building 6 & 6.9 & 1.3 & 0.2 & 0.2 & 0.4 & 5.6 & 0.1 & 0.1 \\
\hline
\end{tabular}

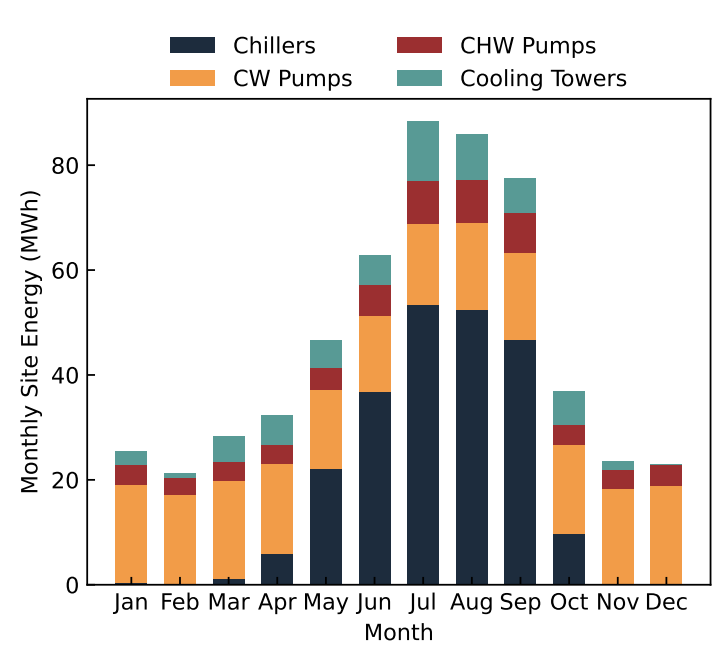

Figure 11: Baseline energy consumption results of the central plant by equipment type.

mode, the cooling tower fans run periodically, but the plant often bypasses the cooling towers to maintain $T_{C W, s e t}$. The cooling tower bypass is used more consistently during $\mathrm{MC}$ mode, largely because $T_{C W, s e t}$ is higher in MC than in FC mode. Further, the CW mass flow rate through the WSE is consistently and significantly greater than the CHW mass flow for both FC and MC modes. This results in a very small $\Delta T$ on the $\mathrm{CW}$ side compared to the CHW side for the WSE (Figure 12c) and chillers (Figure 12f).

\subsection{Energy Efficiency Improvements}

Several energy efficiency measures were simulated based on the validated baseline results. As demonstration cases, three measures that do not require additional financial investments were pursued: (1) optimizing $T_{C W, \text { set }}$ during MC mode, (2) assessing the effectiveness of the WSE, and (3) revising the CW pump flow rate setpoints during FC mode. The results and discussion from these cases are as follows.

\subsubsection{Condenser Water Supply Temperature Optimization}

As seen in Table 4, all three $T_{C W \text {,set }}$ optimizations reduced the plant's annual energy consumption by $2.5 \%$ to $4.4 \%$. Both the Baseline and the Fixed $T_{C W, s e t}$ optimization case (Equation 9) have fixed temperature setpoints. Simply changing the fixed $T_{C W \text {,set }}$ from $15.6^{\circ} \mathrm{C}$ to $18.7^{\circ} \mathrm{C}$ can save $2.5 \%$ energy. While some engineers reduce $T_{C W, \text { set }}$ as low as possible (around $15^{\circ} \mathrm{C}$ ) to allow the chillers to operate at a higher COP [52], there is often a trade-off between chiller energy and cooling tower fan energy [53]. This trade-off was present in this DC simulation. Raising $T_{C W, s e t}$ to a higher level caused chiller energy to increase $5.5 \%$, but saved $42.8 \%$ in cooling tower fan energy. 
(a) Total Efficiency

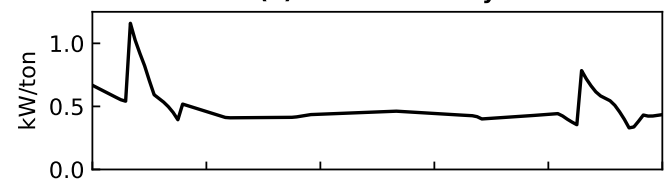

(b) WSE Mass Flow Rates

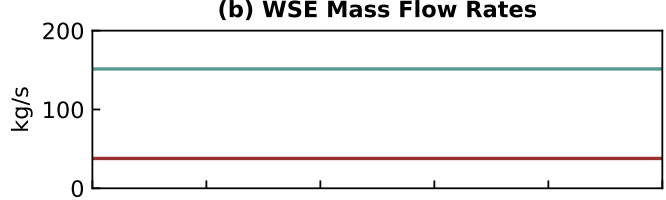

(c) WSE Temperatures

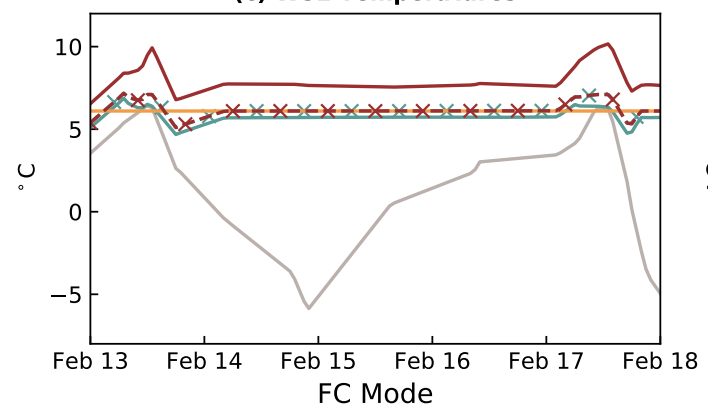

(d) Total Efficiency

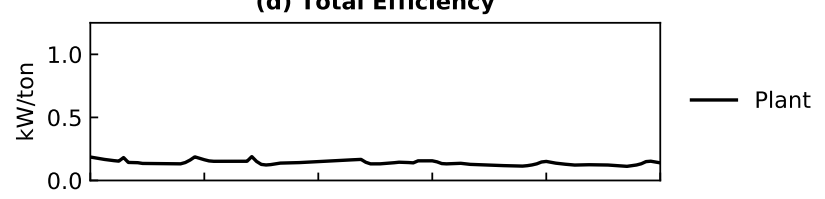

(e) Chiller Mass Flow Rates
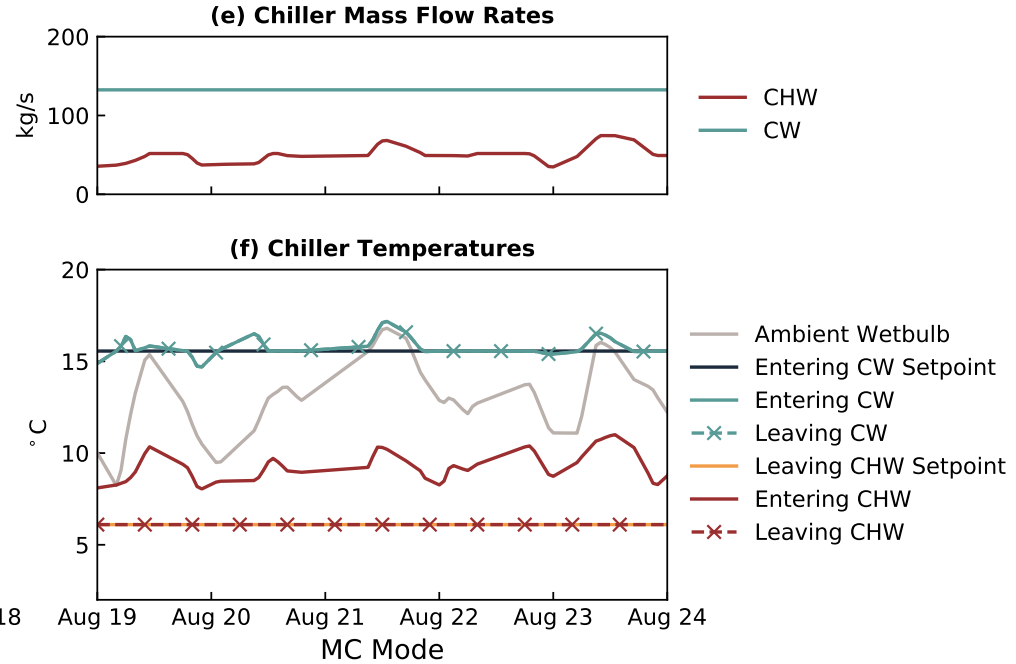

Figure 12: Detailed performance of central plant during FC (left) and MC (right) modes.

These results reinforce the need to consider the entire plant's operation when optimizing control setpoints.

Interestingly, the Fixed $T_{a p p}$ (Equation 10) and Adjusted $T_{a p p}$ (Equation 11) optimizations produced equivalent energy savings, reducing the annual energy consumption by $4.4 \%$. Other researchers similarly studied Fixed and Adjusted $T_{a p p}$ based on wetbulb and part load ratios; for example, Liu and Chuah [54] found that optimizing the Adjusted $T_{a p p}$ (based on wetbulb, chiller load ratio, and chiller and cooling tower fan performance characteristics) saved more than $4 \%$ annual energy for chiller plants without WSE, with the greatest savings occurring in climates with high seasonal variation of $T_{w b}$. However, additional savings from Fixed to Adjusted $T_{a p p}$ were not seen in this case study, primarily due to the presence of the WSE and the central plant's control logics. In this DC system, the optimized $T_{C W, s e t}$ is only applicable during MC mode; thus, the seasonal variation in $T_{w b}$ and part load ratios were reduced to the warm MC seasons only. Based on these results, it is recommended that the plant control $T_{C W, s e t}$ based on a fixed $T_{a p p}$ of $1.9 \mathrm{~K}$ above $T_{w b}$.

Table 4: Condenser water supply temperature optimization results.

\begin{tabular}{|c|c|c|c|c|}
\hline \multirow{2}{*}{ Case } & \multicolumn{2}{|c|}{ Optimized $x$} & \multirow{2}{*}{$\begin{array}{l}\text { Energy } \\
(M W h)\end{array}$} & \multirow{2}{*}{$\begin{array}{r}\text { Savings } \\
(\%)\end{array}$} \\
\hline & Variable & Value & & \\
\hline $\begin{array}{l}\text { Baseline (no } \\
\text { optimization) }\end{array}$ & $x_{1}$ & $15.6^{\circ} \mathrm{C}$ & 551.8 & - \\
\hline Fixed $T_{C W, \text { set }}$ & $x_{1}$ & $18.7^{\circ} \mathrm{C}$ & 537.9 & 2.5 \\
\hline Fixed $T_{a p p}$ & $x_{1}$ & $1.9^{\circ} \mathrm{C}$ & 527.5 & 4.4 \\
\hline Adjusted $T_{a p p}$ & $\begin{array}{l}x_{1} \\
x_{2}\end{array}$ & $\begin{array}{l}2.1^{\circ} \mathrm{C} \\
-0.44\end{array}$ & 527.5 & 4.4 \\
\hline
\end{tabular}

A few limitations of the $T_{C W, s e t}$ optimization should be noted. First, we used a local optimization method, and it is possible that only a local rather than the global optimum was found. Future cases can use a hybrid approach to reduce the search space with a global optimization method, before selecting a local optimum. Second, the energy savings listed assume that the measurements are ideal, but physical $T_{w b}$ sensors can be inaccurate and prone to drift [55]. Thus, the energy savings from the Fixed and Adjusted $T_{a p p}$ cases may be overstated. Despite this, $T_{C W, \text { set }}$ based on wetbulb approach temperatures are adapted in industry $[23,56,18]$.

\subsubsection{The Effectiveness of the Waterside Economizer}

To evaluate the savings that the WSE can bring, we simulated the same plant model but without the WSE. The results are shown in Figure 13. Through this experiment, we determined that the nonintegrated WSE saves $6.9 \%$ of the plant's annual energy consumption. While these savings are notable, the largest benefit of the WSE is the reduction in chiller run time. With the nonintegrated WSE, the total run time of the two chillers decreases from 373 to 172 days per year, which is a $54 \%$ reduction. These large changes in run time extend the service life of the chillers and reduce maintenance costs. Conversely, the total run times of the $\mathrm{CW}$ pumps and cooling towers are higher by approximately 202 days each when the WSE is added. This is because of the control specification that two $\mathrm{CW}$ pumps run during FC mode, and a lower $T_{C W \text {,set }}$ is required to meet the $T_{C H W S}$ setpoint with the WSE than with the chillers, causing the cooling tower fans to run more often. While out of the scope for this study, further energy efficiency improvements are likely possible by reconfiguring the WSE to be connected in 


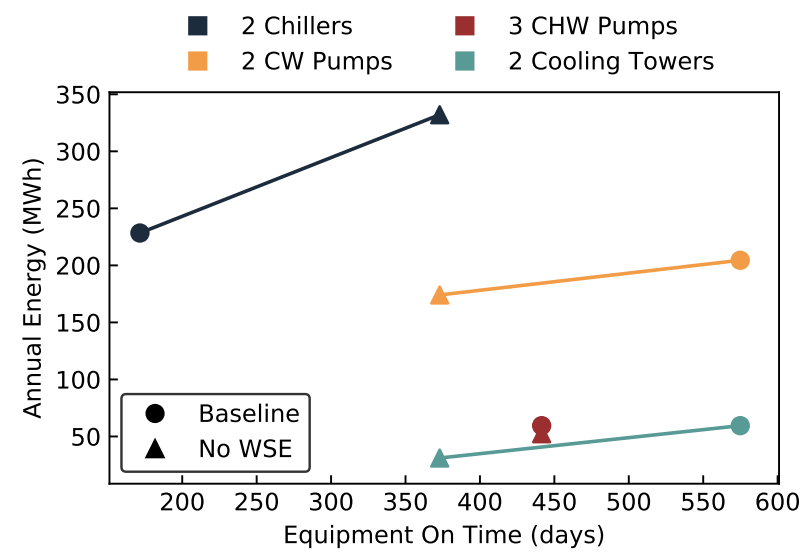

Figure 13: Energy consumption and total running times of equipment for DC system models with (baseline) and without the WSE.

Table 5: Energy results when revising the condenser water flow rate setpoint during FC mode. Flow rates given are per pump.

\begin{tabular}{lcccr}
\hline \multirow{2}{*}{ Case } & \multicolumn{2}{c}{ CW Pump Settings } & Energy & \begin{tabular}{r} 
Savings \\
\cline { 2 - 3 }
\end{tabular} \\
\cline { 2 - 3 } Qty. On & Flow $(\mathrm{kg} / \mathrm{s})$ & $(\mathrm{MWh})$ & $(\%)$ \\
\hline Baseline & 2 & 76 & 551.8 & - \\
1-CWP-126 & 1 & 126 & 522.8 & 5.2 \\
1-CWP-100 & 1 & 100 & 495.3 & 10.2 \\
2-CWP-50 & 2 & 50 & 495.3 & 10.2 \\
\hline
\end{tabular}

series with the chillers on the CHW side (e.g., integrated). An integrated WSE is often the most energy efficient solution because it allows the WSE and chillers to share the cooling load even when the WSE cannot handle the entire load [24, 26, 57].

\subsubsection{Condenser Water Flow Rate Adjustments}

With high CW pumping energy from the baseline model, we tested various pump flow rates and staging configuration to reduce the annual pumping energy during FC mode. The tested cases include operating one CW pump near its maximum flow rate (1-CWP-126), one CW pump at $100 \mathrm{~kg} / \mathrm{s}$ (1-CWP-100), and two CW pumps at $50 \mathrm{~kg} / \mathrm{s}$ each (2-CWP-50). As seen in Table 5, the 1-CWP-126 case saved 5.2\% energy, while the other two cases saved $10.2 \%$. In addition to energy savings, it is beneficial to operate one pump instead of two when possible to improve the pump service life and reduce maintenance costs.

Figure 14 provides further insight into the $\mathrm{CW}$ flow rate adjustments. Interestingly, the 2-CWP-50 case operates at the lowest efficiency during FC mode, around $34 \%$ on average. However, the pumps are also operating at a lower power and with higher temperature differences across the CW-side of the WSE, which results in higher energy savings. These results fall in line with modern industry recommendations to decrease $\mathrm{CW}$ flow rate while increasing the temperature difference to save operating costs [51]. Pump flow rate adjustments such as these present practical cost-free retrofit measures that the central plant can readily implement.
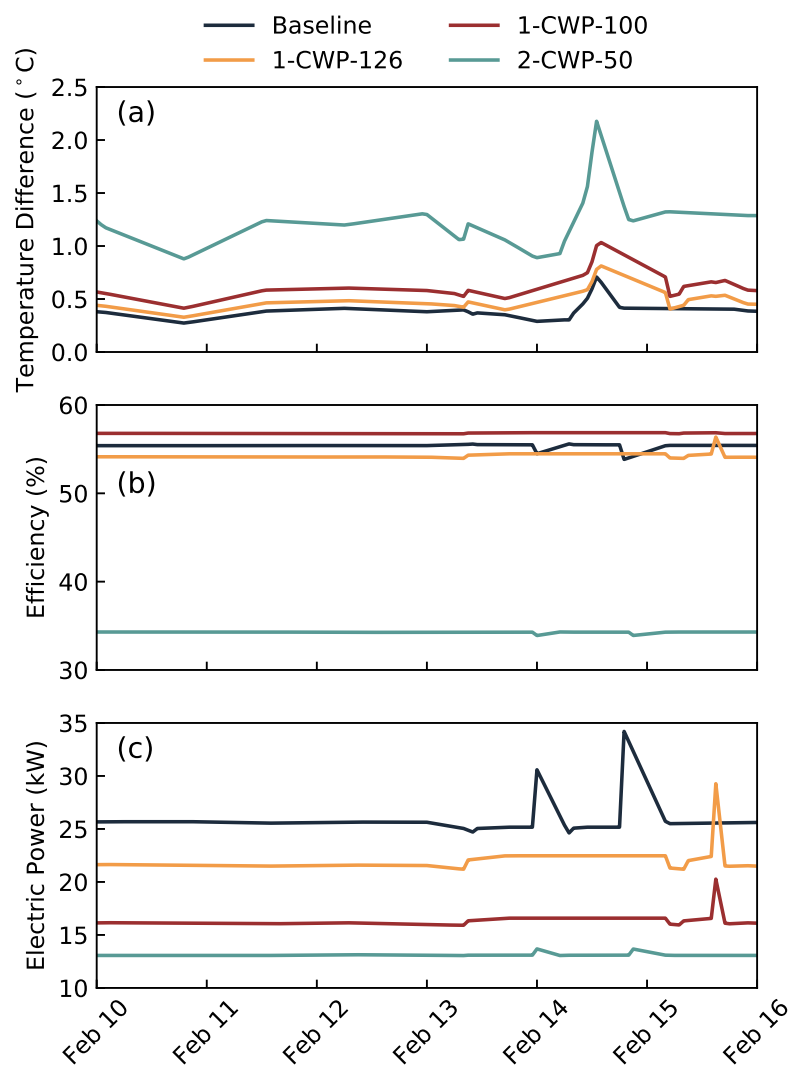

Figure 14: Detailed results of $\mathrm{CW}$ flow rate adjustments, including (a) the $\mathrm{CW}$ temperature difference, (b) the pump operating efficiency, and (c) the total CW pump electrical power.

\subsection{Impact Evaluation}

By improving the energy efficiency of the DC system, additional cost savings and greenhouse gas reduction are achieved. Figure 15 summarizes the results across all simulation cases. All cases except for the case without the WSE reduced energy, operating costs, and carbon emissions. From individual measures, the greatest cost savings came from the Fixed and Adjusted $T_{a p p}$ optimizations, primarily due to the larger decrease in monthly peak powers. Meanwhile, the largest carbon savings from individual measures came from changing the CW pump flow settings during FC mode to 1-CWP-100 and 2-CWP-50. With combined measures of the Fixed $T_{a p p}$ optimization and operating two CW pumps at $50 \mathrm{~kg} / \mathrm{s}$, the best savings were achieved, reducing annual energy consumption by 84.6 MWh (15.3\%), costs by $\$ 930$ (8.9\%), and carbon emissions by 58.0 metric tons $(15.0 \%)$. While the cost dollar savings appear low, this is because of the relatively cheap cost of energy per the pricing structure stated in section 2.8.2. While this work evaluated economic and climate impacts as byproducts of energy efficiency strategies, future work can optimize these impact factors directly.

\subsection{Numerical Performance}

For this case study, all simulations ran using Dymola 2021 on a Linux operating system. The computer contained $32 \mathrm{~GB}$ 

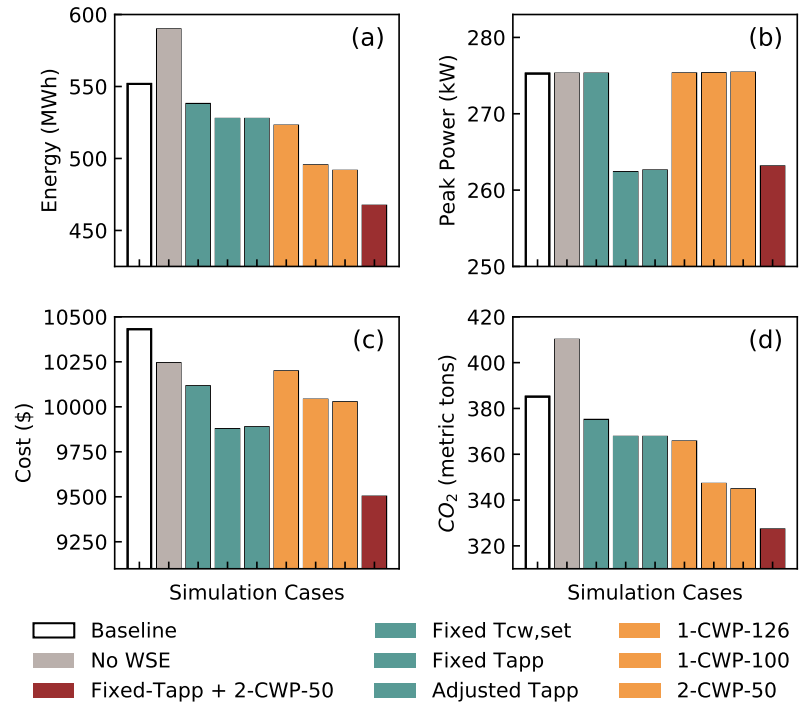

$$
\begin{array}{ll}
\multicolumn{2}{c}{\text { Simulation Cases }} \\
\text { Fixed Tcw, set } & \text { 1-CWP-126 } \\
\text { Fixed Tapp } & \text { 1-CWP-100 } \\
\text { Adjusted Tapp } & \text { 2-CWP-50 }
\end{array}
$$

Figure 15: Impact summary of studied energy measures including (a) total site energy consumption, (b) peak power, (c) energy cost, and (d) carbon emissions, all on an annual basis.

of RAM and a $3.60 \mathrm{GHz}$ Intel ${ }^{\circledR} \mathrm{Xeon}^{\circledR}$ CPU. With CVODE solver and an integration tolerance of $10^{-6}$, the annual simulation took just under 20 minutes. There were 13 nonlinear systems of equations (SOE) in the baseline model, and the largest nonlinear system contained 11 iteration variables. The iteration variables appearing in this largest nonlinear SOE consisted of the CHW mass flow rates through the plant, major equipment (CHW pumps, WSE, chiller), and each building connection, as well as the pressure drop at the CHW bypass check valve.

As a scaling test, the simulation was repeated with the same plant model connected to multiples of the six-building district network (Table 6 and Figure 16). Across all simulation cases, the total cooling demand at the plant was held constant to satisfy system sizing requirements. The numerical problem contained 13 nonlinear SOE, regardless of the number of buildings (n). While the total number of nonlinear SOE was constant with respect to $n$, the dimension of the largest nonlinear system increased in size proportional to $(n+5)$, i.e., linear. The number of continuous time states also increased near linearly with respect to $n$ (more specifically, $O\left(n^{0.85}\right)$ ). These two factors typically have the greatest impact on computing time.

Shown in Figure 16, the computing time scaled by $O\left(n^{2.1}\right)$ and $O\left(s^{2.5}\right)$, where $s$ represents the number of continuous time states. Over the range of district sizes, the computing time scaled closer to linearly when $n$ was less than 20, while the quadratic to cubic scaling was present for districts larger than 20. With the given computer configuration (primarily limited by RAM capacity of $32 \mathrm{~GB}$ ), the maximum number of buildings possible was about 300 .

While scalability studies are limited for DHC, a few previous studies involving small to medium sized districts present similar results. Schweiger et al. [58] found that simulation CPU time scaled linearly with the number of buildings; however, that study only evaluated small district sizes with two to
Table 6: Number quantities of different features in the translated model with respect to the number of buildings in the DC system model. Sizes of nonlinear SOE are given after Dymola's built-in model manipulation.

\begin{tabular}{lccr}
\hline $\begin{array}{l}\text { Number } \\
\text { of } \\
\text { Buildings }\end{array}$ & $\begin{array}{c}\text { Number } \\
\text { of } \\
\text { Equations }\end{array}$ & $\begin{array}{c}\text { Continuous } \\
\text { Time } \\
\text { States }\end{array}$ & $\begin{array}{r}\text { Dimension of } \\
\text { the Largest } \\
\text { Nonlinear SOE }\end{array}$ \\
\hline 6 & 7,291 & 123 & 11 \\
12 & 11,283 & 195 & 17 \\
18 & 15,275 & 267 & 23 \\
24 & 19,267 & 339 & 29 \\
30 & 23,259 & 411 & 35 \\
60 & 43,219 & 771 & 65 \\
90 & 63,179 & 1,131 & 95 \\
120 & 83,139 & 1,491 & 125 \\
\hline
\end{tabular}
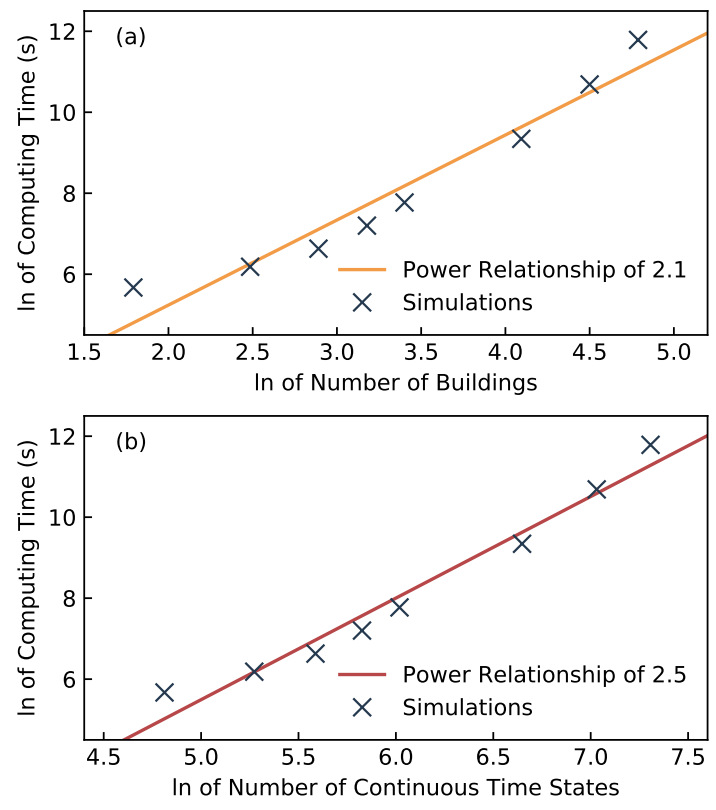

Figure 16: Computing time, presented on a natural $\log -\log (\ln )$ scale, with respect to (a) the total number of interconnected buildings and (b) the number of continuous time states.

nine end users. Our results indicated similar trends, where districts with one to 20 customers had linear scaling, and it was not until medium sized districts were included that the results scaled at higher orders. Similarly, Jorissen et al. [59] simulated districts from 1 to 20 buildings and found computing time scales quadratically with DASSL solver, while Euler integration scaled linearly.

\section{Conclusion}

There is a growing interest and need to include district-scale cooling in advanced modeling platforms. While Modelica has been successful in chiller plants and district heating applications, DC applications remain scarce. The primary intention of this work was to fill this gap while comprehensively including underrepresented plant configurations in DC modeling (e.g., the 
free cooling WSE) and addressing concerns for the suitability of large physics-based Modelica models for large-scale district analysis (e.g., the scalability tests). A systematic methodology is presented from understanding the problem through evaluating system improvements when using Modelica for advanced energy and control analysis of DC systems. In this case study, we included detailed models of the central plant's mechanical and control systems, a complete network topology, and simplified building models to reflect the thermo-fluid dynamics of the real-world system. This enabled us to quantify practical energy efficiency improvements that the system operators can readily implement. All the while, the object-oriented nature of Modelica allows the models to be quickly reconfigured for future studies, such as integrating the WSE, adding thermal storage, or testing novel control schemes featuring deeper building-tothermal-grid interaction.

Beyond energy consumption alone, it is important to identify the impact of our engineering systems on humans and the environment. To this end, we evaluated the electricity costs and carbon emissions as byproducts of the existing system configuration and energy improvement strategies. The best savings were achieved through combined measures of the optimized Fixed $T_{a p p}$ and operating two $\mathrm{CW}$ pumps at $50 \mathrm{~kg} / \mathrm{s}$, reducing annual energy consumption by $84.6 \mathrm{MWh}(15.3 \%)$, costs by $\$ 930$ (8.9\%), and carbon emissions by 58.0 metric tons (15.0\%). Future studies will expand on this preliminary work to optimize both costs and environmental impacts directly.

\section{Acknowledgements}

This material is based upon work supported by the U.S. Department of Energy's Office of Energy Efficiency and Renewable Energy (EERE) under the Advanced Manufacturing Office, Award Number DE-EE0009139. This work was also supported by the Building Technologies Office of the U.S. Department of Energy, under contract numbers DE-AC36-08GO28308 and DE-AC02-05CH11231. Further, this work emerged from the IBPSA Project 1, an international project conducted under the umbrella of the International Building Performance Simulation Association (IBPSA). Project 1 will develop and demonstrate a BIM/GIS and Modelica Framework for building and community energy system design and operation. The authors would also like to thank the campus facilities team for their assistance with data collection, expert advice, and overall support of this project.

\section{References}

[1] International Energy Agency, The Future of Cooling: Opportunities for energy-efficient air conditioning, Tech. rep. (2018).

[2] A. Anderson, B. Rezaie, M. A. Rosen, An innovative approach to enhance sustainability of a district cooling system by adjusting cold thermal storage and chiller operation, Energy 214 (2021) 118949. doi: 10.1016/j . energy.2020.118949.

[3] T. T. Chow, K. F. Fong, A. L. Chan, R. Yau, W. H. Au, V. Cheng, Energy modelling of district cooling system for new urban development, Energy and Buildings 36 (11) (2004) 1153-1162. doi:10.1016/j.enbuild. 2004.04 .002 .
[4] T. Oppelt, T. Urbaneck, U. Gross, B. Platzer, Dynamic thermo-hydraulic model of district cooling networks, Applied Thermal Engineering 102 (2016) 336-345. doi : 10.1016/j . applthermaleng.2016.03.168.

[5] W. Gang, S. Wang, F. Xiao, D. Gao, Performance Assessment of District Cooling System Coupled with Different Energy Technologies in Subtropical Area, Energy Procedia 75 (2015) 1235-1241. doi : 10.1016/j . egypro.2015.07.166.

[6] K. Matsouka, D. Hill, Online Optimization of Cooling Water System in a District Cooling Plant by Using Digital Twin, ASHRAE Transactions 126 (2) (2020) 427-434.

[7] T. Sommer, M. Sulzer, M. Wetter, A. Sotnikov, S. Mennel, C. Stettler, The reservoir network: A new network topology for district heating and cooling, Energy 199 (2020) 117418. doi:10.1016/j.energy . 2020 . 117418.

[8] M. Wetter, J. Hu, Quayside energy system analysis, Tech. Rep. LBNL2001197, Lawrence Berkeley National Laboratory, Berkeley, CA (Mar. 2019).

URL https://simulationresearch.lbl.gov/wetter/ download/LBNL-2001197.pdf

[9] M. Wetter, A View on Future Building System Modeling and Simulation, in: J. L. M. Hensen, R. Lamberts (Eds.), Building Performance Simulation for Design and Operation, Taylor \& Francis Group, Routledge, UK, 2011, Ch. 17.

[10] S. E. Mattsson, H. Elmqvist, Modelica - An international effort to design the next generation modeling language, in: L. Boullart, M. Loccufier, S. E. Mattsson (Eds.), 7th IFAC Symposium on Computer Aided Control Systems Design, Gent, Belgium, 1997, pp. 1-5.

URL http://www.modelica.org/publications/papers/ CACSD97Modelica.pdf

[11] L. Zabala, J. Febres, R. Sterling, S. López, M. Keane, Virtual testbed for model predictive control development in district cooling systems, Renewable and Sustainable Energy Reviews 129 (2020). doi:10.1016/j . rser.2020.109920.

[12] J. Febres, E. Ubieta, R. Sterling, I. del Hoyo, S. López, District Cooling Open Source Library (DCOL) (June 2017). doi : 10.5281/zenodo. 818289.

[13] M. Wetter, W. Zuo, T. S. Nouidui, X. Pang, Modelica Buildings library, Journal of Building Performance Simulation 7 (4) (2014) 253-270. doi : 10.1080/19401493.2013.765506.

[14] S. Frederiksen, S. Werner, District Heating and Cooling, 1st Edition, Studentlitteratur AB, Lund, Sweden, 2013. doi:10.1016/ b0-12-176480-x/00214-x.

[15] R. Sangi, P. Jahangiri, A. Thamm, D. Müller, Dynamic exergy analysis Modelicaß-based tool development: A case study of CHP district heating in Bottrop, Germany, Thermal Science and Engineering Progress 4 (July) (2017) 231-240. doi : 10.1016/j.tsep. 2017.10.008.

[16] E. J. Kim, X. He, J. J. Roux, K. Johannes, F. Kuznik, Fast and accurate district heating and cooling energy demand and load calculations using reduced-order modelling, Applied Energy 238 (January) (2019) 963-971. doi:10.1016/j. apenergy.2019.01.183.

[17] S. Huang, W. Zuo, M. D. Sohn, Amelioration of the cooling load based chiller sequencing control, Applied Energy 168 (2016) 204-215. doi : 10.1016/j . apenergy . 2016.01.035.

[18] S. Huang, W. Zuo, M. D. Sohn, Improved cooling tower control of legacy chiller plants by optimizing the condenser water set point, Building and Environment 111 (2017) 33-46. doi:10.1016/j.buildenv.2016. 10.011.

[19] D. Zhang, P. B. Luh, J. Fan, S. Gupta, Chiller Plant Operation Optimization: Energy-Efficienty Primary-Only and Primary-Secondary Systems, IEEE Transactions on Automation Science and Engineering 15 (1) (2018) 341-355.

[20] Y. Fu, W. Zuo, M. Wetter, J. W. VanGilder, X. Han, D. Plamondon, Equation-based object-oriented modeling and simulation for data center cooling: A case study, Energy and Buildings 186 (2019) 108-125. doi:10.1016/j.enbuild.2019.01.018.

[21] J. Li, Z. Li, Model-based optimization of free cooling switchover temperature and cooling tower approach temperature for data center cooling system with water-side economizer, Energy and Buildings 227 (2020) 110407. doi:10.1016/j.enbuild.2020.110407.

[22] A. Vandermeulen, B. van der Heijde, L. Helsen, Controlling district heating and cooling networks to unlock flexibility: A review, Energy 151 
(2018) 103-115. doi:10.1016/j.energy.2018.03.034.

[23] J. Stein, Waterside economizing in data centers: Design and control considerations, ASHRAE Transactions 115 PART 2 (2009) 192-200.

[24] S. T. Taylor, How to design \& control waterside economizers, ASHRAE Journal 56 (6) (2014) 30-36.

[25] Y. Fu, W. Zuo, M. Wetter, J. W. VanGilder, P. Yang, Equation-based object-oriented modeling and simulation of data center cooling systems, Energy and Buildings 198 (2019) 503-519. doi:10.1016/j . enbuild. 2019.06.037.

[26] C. Fan, K. Hinkelman, Y. Fu, W. Zuo, S. Huang, C. Shi, N. Mamaghani, C. Faulkner, X. Zhou, Open-source Modelica models for the control performance simulation of chiller plants with water-side economizer, Applied Energy (2021).

[27] K. Hinkelman, J. Wang, C. Fan, W. Zuo, A. Gautier, M. Wetter, N. Long, A Case Study on Condenser Water Supply Temperature Optimization with a District Cooling Plant, in: The 14th International Modelica Conference, Linköping, Sweden, 2021. doi : 10.31224/osf .io/rfc8p.

[28] J. McLaren, S. Mullendore, Identifying Potential Markets for Behindthe-Meter Battery Energy Storage: A Survey of U.S. Demand Charges, Tech. rep., Clean Energy Group, National Renewable Energy Laboratory (aug 2017).

URL https://www.cleanegroup.org/wp-content/uploads/ NREL_BatteryStorage_2017.pdf

[29] Modelica Association, Modelica Standard Library - Version 3.2.3 (2019). URL https://doc.modelica.org/Modelica3.2.3/Resources/ helpDymola/Modelica.html

[30] D. Müller, M. Lauster, A. Constantin, M. Fuchs, P. Remmen, AIXLIB - An Open-Source Modelica Library within the IEA-EBC Annex 60 Framework, in: BauSIM, no. November, Dresden, Germany, 2016, pp. 3-9.

[31] J. Van Roy, B. Verbruggen, J. Driesen, Ideas for Tomorrow: New Tools for Integrated Building and District Modeling, IEEE Power and Energy Magazine 11 (5) (2013) 75-81. doi : 10.1109/MPE . 2013. 2268815.

[32] C. Nytsch-Geusen, J. Huber, M. Ljubijankic, J. Rädler, Modelica BuildingSystems - eine Modellbibliothek zur Simulation komplexer energietechnischer Gebäudesysteme, Bauphysik 35 (1) (2013) 21-29. doi : 10.1002/bapi. 201310045.

[33] Dassault Systèmes AB, Dymola User Manual 1A: Introduction, Getting Started, and Installation (March 2020) (2020).

[34] Modelon, OPTIMICA Compiler Toolkit - Overview (2016). URL https://www.modelon.com/support/ optimica-compiler-toolkit-overview/

[35] Modelon, JModelica (2019). URL https : //jmodelica.org/

[36] P. Fritzson, A. Pop, K. Abdelhak, A. Asghar, B. Bachmann, W. Braun, D. Bouskela, R. Braun, L. Buffoni, F. Casella, R. Castro, R. Franke, D. Fritzson, M. Gebremedhin, A. Heuermann, B. Lie, A. Mengist, L. Mikelsons, K. Moudgalya, L. Ochel, A. Palanisamy, V. Ruge, W. Schamai, M. Sjölund, B. Thiele, J. Tinnerholm, P. Östlund, The OpenModelica integrated environment for modeling, simulation, and modelbased development, Modeling, Identification and Control 41 (4) (2020) 241-285. doi:10.4173/MIC.2020.4.1.

[37] A. C. Hindmarsh, R. Serban, D. R. Reynolds, User documentation for CVODE v5.1.0 (SUNDIALS v5.1.0), Tech. rep., Lawrence Livermore National Laboratory (2020)

URL https://computing.llnl.gov/projects/sundials/ sundials-software

[38] Lawrence Berkeley National Laboratory, Simulation Performance (2020).

URL https://simulationresearch.lbl.gov/modelica/ userGuide

[39] F. E. Cellier, E. Kofman, Continuous System Simulation, Springer, New York, NY, USA, 2006.

[40] J. Keirstead, M. Jennings, A. Sivakumar, A review of urban energy system models: Approaches, challenges and opportunities, Renewable and Sustainable Energy Reviews 16 (6) (2012) 3847-3866. doi:10.1016/ j.rser.2012.02.047.

[41] I. De Jaeger, On the impact of input data uncertainty on the reliability of urban building energy models, Phd dissertation, KU Leuven (2021). URL https : //bwk. kuleuven. be/bwf/PhDs/PhDDeJaeger

[42] ASHRAE, ASHRAE Guideline 14-2014: Measurement of Energy, De- mand, and Water Savings, Tech. rep., Atlanta, GA (2014).

[43] Y. Ye, K. Hinkelman, J. Zhang, W. Zuo, G. Wang, A methodology to create prototypical building energy models for existing buildings: A case study on U.S. religious worship buildings, Energy and Buildings 194 (2019) 351-365. doi : 10.1016/j . enbuild.2019.04.037.

[44] M. Hydeman, G. Zhou, Optimizing chilled water plant control, ASHRAE Journal 49 (6) (2007) 44-54.

[45] A. Pfeiffer, Optimization Library for Interactive Multi-Criteria Optimization Tasks, in: Proceedings of the 9th International Modelica Conference, Vol. 76, Munich, Germany, 2012, pp. 669-680. doi:10.3384/ ecp12076669.

[46] Y. Ye, Y. Lou, W. Zuo, E. Franconi, G. Wang, How do electricity pricing programs impact the selection of energy efficiency measures? - A case study with U.S. Medium office buildings, Energy and Buildings 224 (2020) 110267. doi:10.1016/j.enbuild.2020.110267.

[47] A. Sharma, A. Saxena, M. Sethi, V. Shree, Varun, Life cycle assessment of buildings: A review, Renewable and Sustainable Energy Reviews 15 (2011) 871-875. doi:10.1016/j.rser.2010.09.008.

[48] W. Cole, S. Corcoran, N. Gates, T. Mai, P. Das, 2020 Standard Scenarios Report: A U.S. Electricity Sector Outlook, Tech. Rep. NREL/TP-6A2077442, National Renewable Energy Laboratory, Golden, CO (2020). URL https ://www.nrel.gov/docs/fy21osti/77442.pdf

[49] B. van der Heijde, M. Fuchs, C. Ribas Tugores, G. Schweiger, K. Sartor, D. Basciotti, D. Müller, C. Nytsch-Geusen, M. Wetter, L. Helsen, Dynamic equation-based thermo-hydraulic pipe model for district heating and cooling systems, Energy Conversion and Management 151 (2017) 158-169. doi:10.1016/j.enconman.2017.08.072.

[50] A. C. Lo, P. Jones, F. W. Yik, Effects of pumping station configuration on the energy performance of district cooling systems, Building Services Engineering Research and Technology 38 (3) (2017) 287-308. doi: 10 . $1177 / 0143624416680019$

[51] M. Schwedler, B. Bakkum, Condenser Water System Savings: Optimizing flow rates and control, Trane Engineers Newsletter 41 (3) (2012) 1-8.

[52] F. W. Yu, K. T. Chan, Optimization of water-cooled chiller system with load-based speed control, Applied Energy 85 (10) (2008) 931-950. doi : 10.1016/j.apenergy . 2008.02.008.

[53] L. Lu, W. Cai, Y. C. Soh, L. Xie, S. Li, HVAC system optimization Condenser water loop, Energy Conversion and Management 45 (4) (2004) 613-630. doi:10.1016/S0196-8904(03)00181-X.

[54] C. W. Liu, Y. K. Chuah, A study on an optimal approach temperature control strategy of condensing water temperature for energy saving, International Journal of Refrigeration 34 (3) (2011) 816-823. doi : 10.1016/j.ijrefrig. 2011.01.001.

[55] K. Zheng, J. Watt, C. Wang, Y. K. Cho, Development and implementation of a virtual outside air wet-bulb temperature sensor for improving watercooled chiller plant energy efficiency, Sustainable Cities and Society 23 (2016) 11-15. doi:10.1016/j.scs . 2016.02.012.

[56] S. T. Taylor, Optimizing Design \& Control Of Chilled Water Plants: Part 5: Optimized Control Sequences, ASHRAE Journal 54 (June) (2012) 5674.

[57] Armstrong Fluid Technology, Water cooled chiller plant with economiser, Tech. rep., Toronto, Ontario (2015).

[58] G. Schweiger, F. Jorissen, H. Runvik, L. Helsen, Equation-based modelling for dynamic optimization of district scale energy systems - a scalability study, in: 2019 International Conference on Smart Energy Systems and Technologies (SEST), IEEE, Porto, Portugal, 2019. doi: 10.1109/sest. 2019.8849039.

[59] F. Jorissen, G. Reynders, R. Baetens, D. Picard, D. Saelens, L. Helsen, Implementation and verification of the IDEAS building energy simulation library, Journal of Building Performance Simulation 11 (6) (2018) 669688. doi : 10.1080/19401493.2018.1428361.

\section{Appendix A. Distribution Network Parameters}

See Table A.1. 
Table A.1: Distribution network sizing for each single pipe. The same sizing applies to both supply and return pipes.

\begin{tabular}{lcr}
\hline Segment No. & Length $(\mathrm{m})$ & Nominal Diameter $(\mathrm{cm})$ \\
\hline 1 & 31 & 45.7 \\
2 & 31 & 20.3 \\
3 & 27 & 45.7 \\
4 & 26 & 20.3 \\
5 & 31 & 45.7 \\
6 & 104 & 25.4 \\
7 & 18 & 15.2 \\
8 & 85 & 15.2 \\
9 & 77 & 45.7 \\
10 & 109 & 20.3 \\
11 & 225 & 20.4 \\
\hline
\end{tabular}

